\title{
Estrogen-Induced Alteration of $\mu$-Opioid Receptor Immunoreactivity in the Medial Preoptic Nucleus and Medial Amygdala
}

\author{
Clair B. Eckersell, Paul Popper, and Paul E Micevych \\ Department of Neurobiology, School of Medicine, and the Laboratory of Neuroendocrinology, Brain Research Institute, \\ University of California Los Angeles, Los Angeles, California 90095-1763
}

The $\mu$-opioid receptor ( $\mu$-OR), like most G-protein-coupled receptors, is rapidly internalized after agonist binding. Although opioid peptides induce internalization in vivo, there are no studies that demonstrate $\mu$-OR internalization in response to natural stimuli. In this study, we used laser-scanning microscopy to demonstrate that estrogen treatment induces the translocation of $\mu$-OR immunoreactivity ( $\mu$-ORi) from the membrane to an internal location in steroid-sensitive cell groups of the limbic system and hypothalamus. Estrogen-induced internalization was prevented by the opioid antagonist naltrexone, suggesting that translocation was largely dependent on release of endogenous agonists. Estrogen treatment also altered the pattern of $\mu$-ORi at the bright-field light microscopic level. In the absence of stimulation, the majority of immunoreactivity is diffuse, with few definable $\mu$-OR + cell bodies or processes. After stimulation, the density of distinct processes filled with $\mu$-ORi was significantly increased. We interpreted the increase in the number of $\mu$-OR + processes as indicating increased levels of internalization. Using this increase in the density of $\mu$-OR + fibers, we showed that treatment of ovariectomized rats with estradiol benzoate induced a rapid and reversible increase in the number of fibers. Significant internalization was noted within $30 \mathrm{~min}$ and lasted for $>24 \mathrm{hr}$ after estrogen treatment in the medial preoptic nucleus, the principal part of the bed nucleus, and the posterodorsal medial amygdala. Naltrexone prevented the increase of $\mu$-OR + processes. These data imply that estrogen treatment stimulates the release of endogenous opioids that activate $\mu$-OR in the limbic system and hypothalamus providing a "neurochemical signature" of steroid activation of these circuits.

Key words: receptor internalization; neurochemistry of reproduction; steroid hormones; opioid peptides; G-protein-coupled receptors; hypothalamus
Neurons in the limbic system and hypothalamus form a circuit that regulates reproductive behavior. The processing of sensory and somatic information by these limbic-hypothalamic neurons is dependent on the hormonal state of the animal. Circulating steroids regulate the synthesis of several neurotransmitters in the neurons of the posterodorsal part of the medial amygdala (MeApd), the bed nucleus of the stria terminalis (BST), and the medial preoptic nucleus (MPN). In females, estrogen alters the activity of this circuit resulting in a stimulation of reproductive behavior. Although a large body of evidence indicates that estrogen induces the expression of a number of transmitters, including the endogenous opioid peptides (Dupont et al., 1980; Priest et al., 1995; Micevych et al., 1996), there is a paucity of information about the time course of estrogen-induced release of these compounds. Determining the release of neurotransmitters in specific hypothalamic and limbic nuclei is problematic because the cell groups are compact and the amounts of neuropeptides released are small (Sinchak et al., 1997b). Thus, the anatomy of the

\footnotetext{
Received Dec. 9, 1997; revised Feb. 27, 1998; accepted March 5, 1998.

This research was supported by National Institutes of Health Grants NS21220 and HD07228 and National Institute on Drug Abuse Grant DA05010. We thank Wesley Tsai, Paul Nguyen, Victor Yu, and Allison Norell for their technical assistance, and Drs. Kevin Sinchak and Christopher Evans for their insightful comments on this manuscript. The University of California Los Angeles Mental Retardation Research Center Media Core was helpful with the preparation of illustrations.

Correspondence should be addressed to Dr. Paul E Micevych, Department of Neurobiology, University of California Los Angeles School of Medicine, Los Angeles, CA 90095-1763.

Copyright (ㄷ) 1998 Society for Neuroscience $\quad 0270-6474 / 98 / 183967-10 \$ 05.00 / 0$
}

hypothalamus and the nature of peptidergic transmission generally preclude the direct measurement of neuropeptide release from morphologically discrete regions.

Endogenous opioid peptides are widely distributed throughout the limbic and hypothalamic cell groups and are some of the most extensively studied transmitters involved in the regulation of female reproduction. Several lines of evidence implicate endogenous opioid peptides in the regulation of puberty (Wilkinson and Bhanot, 1982; Bhanot and Wilkinson, 1983; Sirinathsinghji et al., 1985; Rodriguez et al., 1993), secretion of luteinizing hormone (Cicero et al., 1979; Kalra and Kalra, 1984; Piva et al., 1985; Zhen and Gallo, 1992) through alterations of luteinizing hormone-releasing hormone (LHRH) release (Bicknell, 1985; Kalra, 1986; Piva et al., 1986; Jacobson and Kalra, 1989), and female sexual behavior (Wiesner and Moss, 1986a,b; Pfaus and Gorzalka, 1987; Vathy et al., 1991; Pfaus and Pfaff, 1992; Allen et al., 1993; Olster, 1994; Torii et al., 1995, 1996; Sinchak et al., 1997a). Endogenous opioid peptides also modulate the estrogeninduced expression and release of other transmitters that alter reproductive behavior, such as cholecystokinin and substance $\mathrm{P}$ (Eckersell and Micevych, 1997; Sinchak et al., 1997b), norepinephrine (Vathy et al., 1991), and serotonin (Allen et al., 1993).

The major opioid receptor mediating the action of endogenous opioids on reproduction is the $\mu$-OR. The $\mu$-OR is a typical seven-membrane pass, G-protein-coupled receptor that undergoes agonist-induced receptor internalization. Internalization has been suggested to contribute to receptor desensitization and ligand degradation (Senogles et al., 1990; Kobilka, 1992; Caron 

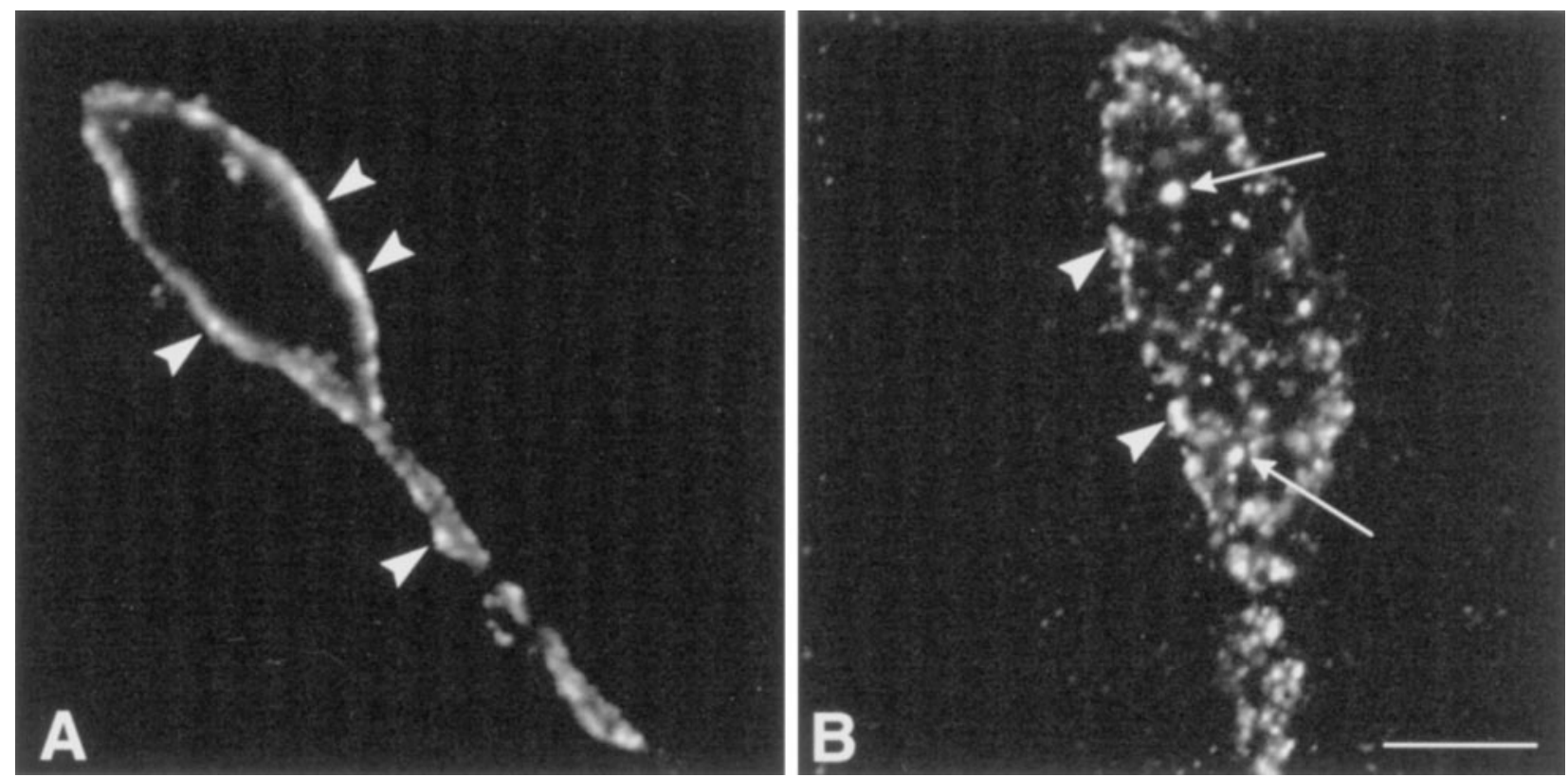

Figure 1. Confocal image of cells in the medial preoptic nucleus stained with antibodies against $\mu$-OR. $A$, From an OVX rat, the $\mu$-ORi is associated with the plasma membrane. $B$, From an estrogen-treated rat, the $\mu$-ORi is translocated to the interior of the cell. Magnification, $800 \times$.

and Lefkowitz, 1993; Lefkowitz et al., 1993; von Zastrow et al., 1993; Garland et al., 1996). Sternini et al. (1996) have shown that injections of the nonselective opioid agonist etorphine produce internalization of $\mu$-ORi in enteric neurons. We have shown that systemic etorphine injection produces a redistribution of $\mu-\mathrm{ORi}$ in the hypothalamus such that the density of immunoreactive processes was increased. In the medial preoptic area, treatment of ovariectomized females with exogenous estrogen qualitatively induced the same type of redistribution of $\mu$-ORi (Micevych et al., 1997). This redistribution of immunoreactivity appears to represent the internalization of $\mu$-OR after activation. Mantyh et al. (1995a,b) and Allen et al. (1997) used the phenomenon of agonist-induced internalization of substance $\mathrm{P}$ receptor immunoreactivity to determine the activation of neurons after specific somatosensory stimuli. These studies suggested that monitoring the redistribution of G-protein-coupled receptors can be used to determine the neurochemical signature of a stimulus (Allen et al., 1997).

In the present study, we correlated $\mu$-OR internalization with the increase in the number of discrete $\mu$-OR + processes, established its sensitivity to antagonists, and used the redistribution of $\mu$-ORi to monitor the time course of ligand-activated internalization as a marker for endogenous opioid release after estrogen stimulation of the limbic system and hypothalamus.

\section{MATERIALS AND METHODS}

\section{$\mu$-OR immunohistochemistry}

Animals. Adult female Long-Evans rats (65 to 75 d old; Harlan Sprague Dawley, Indianapolis, IN) were ovariectomized (OVX) by the supplier and shipped to UCLA. On arrival, animals were maintained in the UCLA vivarium under a $12 \mathrm{hr}$ light/dark photoperiod (lights on at 6:00 A.M.) with rodent chow and water available ad libitum. All of the procedures were approved by the Chancellor's Animal Research Committee at UCLA.

Estrogen stimulation. OVX rats were implanted with a subcutaneous cannula (polyethylene tubing; Becton Dickinson, Cockeysville, MD; inner diameter, $0.86 \mathrm{~mm}$; outer diameter, $1.52 \mathrm{~mm}$ ) under light ether anesthesia $3 \mathrm{~d}$ before estradiol benzoate (EB) injection. Animals were handled daily, and EB (50 $\mu \mathrm{g}$ in $0.2 \mathrm{ml}$ of safflower oil) was injected via the cannula. This procedure has been shown to reduce injection stress and its effects on the enkephalinergic circuit (Eckersell et al., 1996). Immediately after EB injection or $0.5,1,2,4,6,12,24,48,72$, or $96 \mathrm{hr}$ later $(n=4$ per time point) rats were deeply anesthetized $(40 \mathrm{mg} / \mathrm{kg}$ sodium pentobarbital) and transcardially perfused with physiological saline $\left(4^{\circ} \mathrm{C}\right)$ followed by $4 \%$ paraformaldehyde in 0.1 M Sörensen's phosphate buffer $\left(4^{\circ} \mathrm{C}\right)$. As a control, animals were injected with the opiate antagonist naltrexone $(0.5 \mathrm{mg} / \mathrm{ml}$ in saline for total of $10 \mathrm{mg} / \mathrm{kg}$ of body weight) 24 and $4 \mathrm{hr}$ before perfusion and injected with EB $(50 \mu \mathrm{g}$ in $0.2 \mathrm{ml}$ safflower oil) $4 \mathrm{hr}$ before perfusion. Brains were removed, post-fixed for $4 \mathrm{hr}$ in the paraformaldehyde solution, and cryoprotected in $15 \%$ sucrose in $0.1 \mathrm{M}$ PBS, $\mathrm{pH}$ 7.5. Serial coronal sections $(30 \mu \mathrm{m})$ through the medial preoptic area (MPO), and MeApd were obtained on a freezing microtome (Zeiss Microm, Thornwood, NY) and immunocytochemically stained.

Immunocytochemical localization of $\mu$-OR. Brain sections were processed for $\mu$-OR immunocytochemistry using an affinity-purified antibody raised in rabbit against a synthetic fragment (LENLEAETAPLP) corresponding to the intracellular $\mathrm{C}$ terminus of rat $\mu$-OR $\left(\mu\right.$-OR $\mathrm{OR}_{387-398}$; a gift from C. Evans and B. Anton, UCLA). Free-floating tissue sections were washed in PBS followed by incubation in $10 \%$ normal goat serum, $5 \%$ bovine serum albumin, and $0.3 \%$ Triton X-100 in PBS with for 30 min. Sections were then incubated for $48 \mathrm{hr}$ with the affinity-purified $\mu$-OR antibody $(1: 200-1: 3200)$ at $4^{\circ} \mathrm{C}$. Antiserum was diluted in PBS with $10 \%$ normal goat serum, $5 \%$ bovine serum albumin, and $0.3 \%$ Triton $\mathrm{X}-100$. After $48 \mathrm{hr}$, sections were washed in PBS, and alternate sections were processed with an avidin-biotin-peroxidase complex and either a fluorescent label for laser scanning confocal microscopy or the chromogen 3,3'-diaminobenzidine tetrahydrochloride (DAB) for light microscopy.

Sections processed for fluorescence were incubated in blocking buffer (Tyramide signal amplification kit; NEN Life Science Products, Boston, MA) and then in biotin-conjugated goat anti-rabbit IgG (Vector Laboratories, Burlingame, CA; 1:200) for $1 \mathrm{hr}$. Tissue was then washed in TBS and incubated in streptavidin-horseradish peroxidase (NEN; 1:100) for $30 \mathrm{~min}$, washed, and then incubated for $8 \mathrm{~min}$ in fluorescein-conjugated tyramide (Tyramide signal amplification kit, NEN; 1:50). Sections were again washed in $0.1 \mathrm{~m}$ Tris buffer and mounted on Superfrost Plus slides (Fisher Scientific, Houston, TX). Mounted sections were air-dried and coverslipped using Vectashield mounting medium (Vector).

Sections processed for bright-field microscopy were incubated with biotinylated goat anti-rabbit IgG $(1: 200,1 \mathrm{hr})$ followed by an avidinbiotin complex coupled to horseradish peroxidase (1:50, $1 \mathrm{hr}$; Vectastain Elite, Vector) and visualized with the chromogen DAB (Sigma, St. Louis, MO). Sections were mounted on Superfrost Plus slides (Fisher 

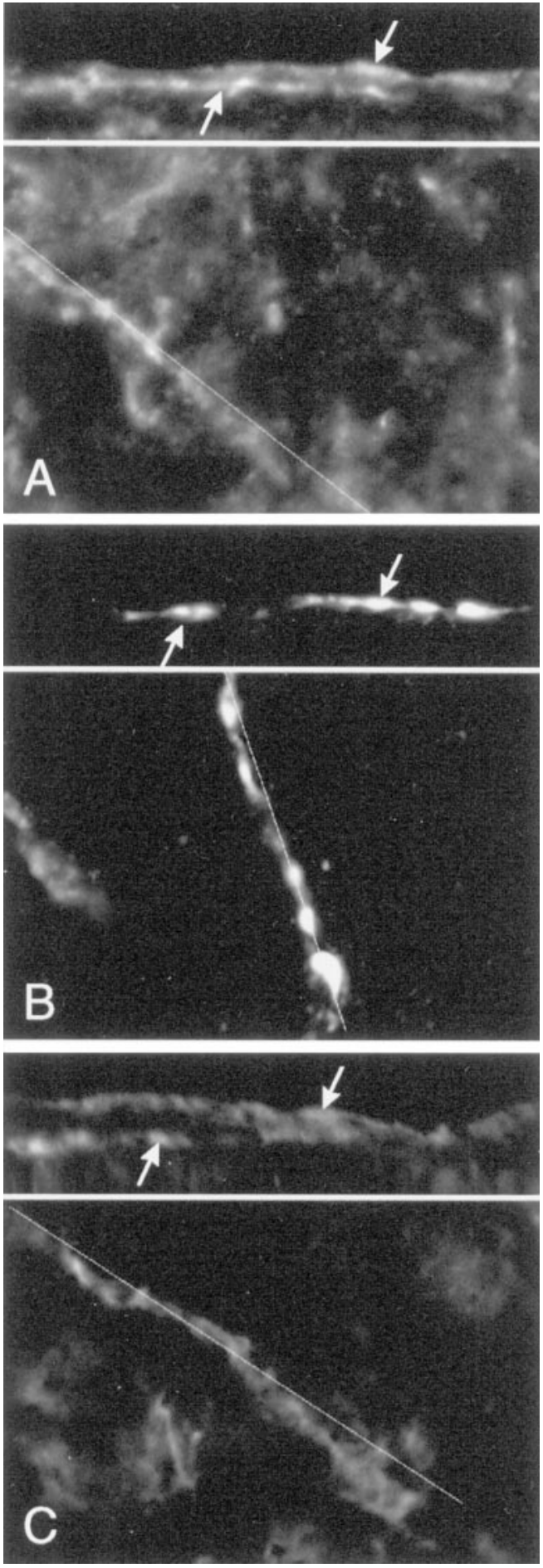

Figure 2. Confocal photomicrographs of $\mu$-ORi processes in the medial part of the medial preoptic nucleus from an $\operatorname{OVX}(A), \operatorname{OVX}$ plus $\mathrm{EB}(B)$, and OVX plus EB rat pretreated with naltrexone $(C)$. Immunoreactive fibers were optically sectioned in the $z$-axis along the line indicated at the bottom of each photograph and rotated $90^{\circ}$. The resulting image (top of each panel) illustrates that the $\mu$-ORi is associated with the plasma membrane (arrowheads) in ovariectomized rats $(A)$. Treatment with estrogen induced a translocation of the $\mu$-ORi into the interior of the neural process $(B)$. The neural process had also become more varicose $(B$, arrowheads). Neural processes from rats treated with naltrexone and then estrogen had $\mu$-ORi associated with the plasma membrane $(C$, arrowheads). The immunolabeling in naltrexone-treated rats was consistently less intense than in tissue from OVX and estrogen-treated rats. Magnification, $2400 \times$.

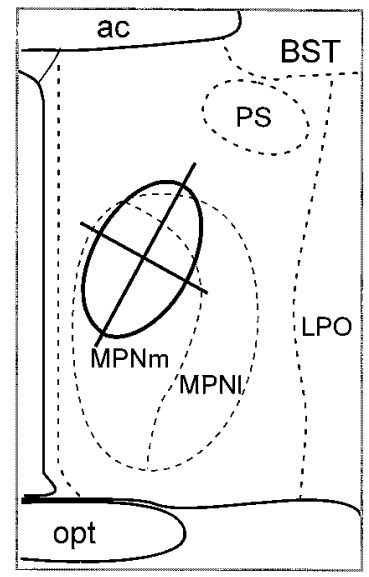

Figure 3. Schematic representation of the quantification method of $\mu$-OR + fibers in the medial part of the medial preoptic nucleus (MPNm). $\mu$-OR + fibers that touched or intersected the perpendicular lines superimposed on the $\mu$-ORi plexus within MPN were counted. The density of immunoreactive fibers was calculated by dividing the number of processes by the total length of the lines within $\mu$-ORi plexus. The same type of analysis was applied to the MeApd. Results are presented in Figure 7. $a c$, Anterior commissure; $B S T$, bed nucleus of the stria terminalis; $M P N l$, lateral portion of the MPN; $L P O$, lateral preoptic area; $P S$, parastrial nucleus.

Scientific), processed through a series of graded alcohols and xylene, and coverslipped with Permount mounting medium (Fisher Scientific). To minimize variability, animals were processed in groups of one animal from each time point.

Analysis. Specimens were examined with a Zeiss LSM 410 laserscanning confocal microscope system (Zeiss, Thornwood, NY). The excitation source was a krypton-argon laser (Coherent, Santa Clara, CA) with output at 488, 568, and $633 \mathrm{~nm}$. Fluorescein fluorescence was imaged with a $488 \mathrm{~nm}$ emission filter and a $515-540 \mathrm{~nm}$ bandpass filter. The resulting images were created by projecting several optical sections obtained at different $1 \mu \mathrm{m}$ intervals through the section in the $z$-axis (Fig. 1). To demonstrate the location of $\mu-\mathrm{ORi}$, a single $0.5 \mu \mathrm{m}$ optical section in the $z$-plane was obtained along the major axis and rotated $90^{\circ}$ to visualize the interior of the process (Fig. 2). Images were adjusted for brightness and contrast using the Zeiss LSM-PC program before printing with a Kodak XLS 8600 PF color printer (Eastman Kodak, Rochester, NY). $\mu$-ORi was considered internalized when the majority of immunoreactivity was observed in the vesicles within the cytoplasm of neuronal cell bodies and processes (Fig. 1). An increased number of distinctive $\mu$-OR-immunoreactive somata and processes present in tissue sections stained with $\mathrm{DAB}$ were correlated with an increase in the degree of receptor internalization as shown by fluorescence laser-scanning microscopy. To obtain an estimate of the relative level of internalization, the density of $\mu$-OR-immunoreactive processes was determined by superimposing a set of perpendicular lines onto images of the MPN (Fig. 3) and MeApd at four to six levels throughout the rostrocaudal extent of the nucleus and counting all of the distinct, $\mu$-OR-immunolabeled processes that intersect or touch the line (modified from Eckersell et al., 1992; Priest et al., 1995). Density was calculated by normalizing the number of processes to a $100 \mu \mathrm{m}$ line length. The density of $\mu$-ORi fibers was also determined in sections throughout the globus pallidus, an area that is outside of the estrogen-sensitive limbic-hypothalamic circuit. Treatment groups for each nucleus were compared using one-way ANOVA with Bonferroni's post hoc comparisons (Sigma Stat, Jandel Scientific, San Rafael, CA), and differences at the $p<0.05$ level were considered significant.

\section{$\mu$-OR autoradiography}

Animals. OVX rats ( $n=4$ per group) were injected with EB $(50 \mu \mathrm{g}$ in $0.2 \mathrm{ml}$ of safflower oil). The animals were decapitated at the time of injections or 6,12 , and $24 \mathrm{hr}$ later. Brains were removed and blocked in the coronal plane, with the aid of a Brain Matrix (Activational Systems, Warren MI) into a block extending caudally from the organum vasculosum, lamina terminalis to the mammillary bodies. The brain was then 

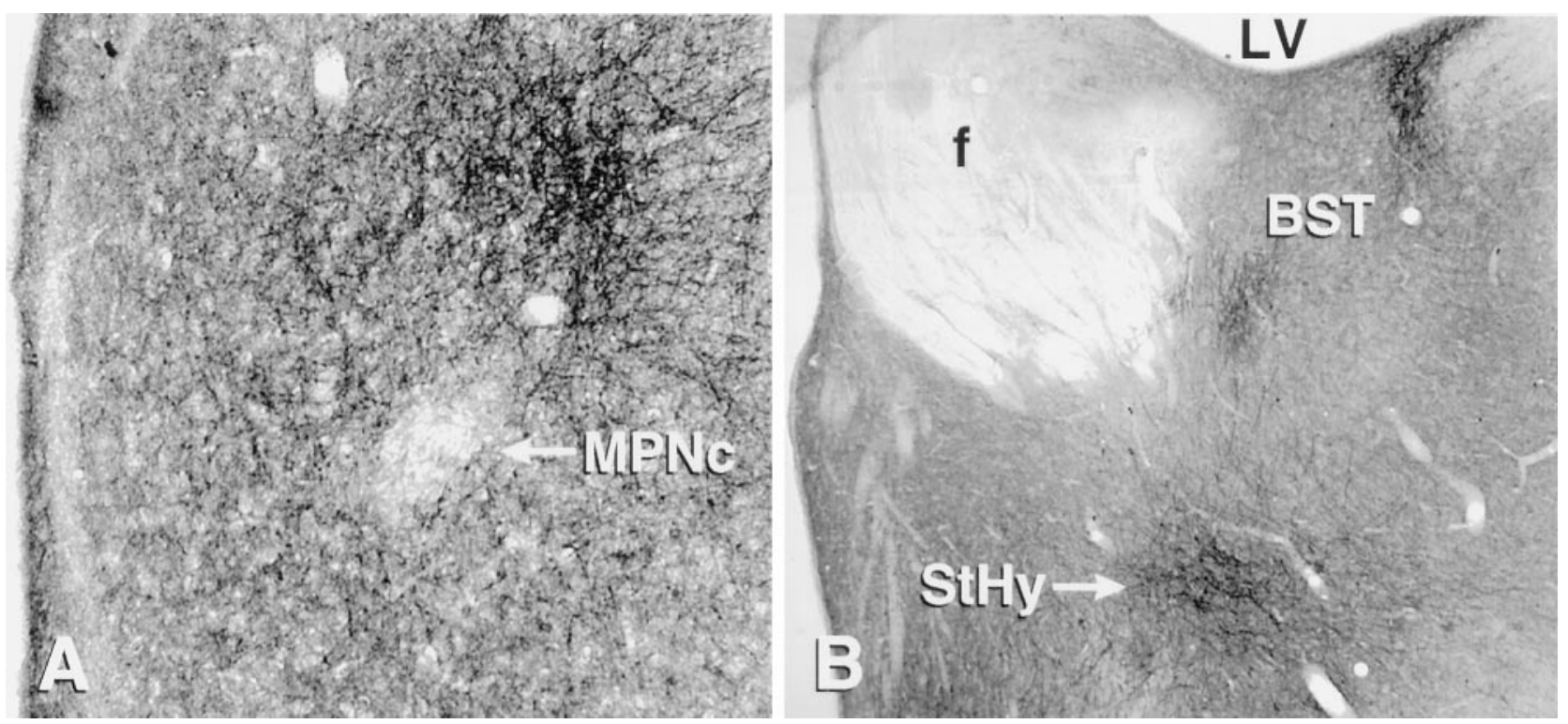

Figure 4. Photomicrographs of the medial preoptic area stained with antibodies against the $\mu$-OR. $A, \mu$-OR-immunoreactive fibers are concentrated in the medial part of the medial preoptic nucleus, surrounding the central part (MPNc), which is devoid of labeled fibers. $\mu$-ORi fibers form a dense plexus dorsolateral to the MPNc. $B$, Other concentrations of $\mu$-ORi fibers at the level of the MPNc, including the striohypothalamic nucleus (StHy) and the principal portion of the bed nucleus of the stria terminalis $(B S T) . f$, Fornix; $L V$, lateral ventricle.

embedded in OCT embedding medium (Sakura Finetek, Torrance, CA) and frozen on dry ice snow. The tissues were sectioned at $10 \mu \mathrm{m}$ with a cryostat, mounted on Superfrost Plus slides (Fisher Scientific), and were stored at $-70^{\circ} \mathrm{C}$ until used for receptor binding.

$\left[{ }^{3} H\right]\left[D-\mathrm{Ala}^{2}-\mathrm{N}-\mathrm{Me}-\mathrm{Phe}^{4}, \mathrm{Gly}^{-o l^{5}}\right]$-enkephalin binding. The protocol for $\mu$-OR autoradiography was adapted from that of Mansour et al. (1995). Slide-mounted tissue sections were brought to room temperature and incubated for $30 \mathrm{~min}$ at room temperature in $50 \mathrm{~mm}$ Tris- $\mathrm{HCl}$, $\mathrm{pH}$ 7.5. Sections were incubated for $60 \mathrm{~min}$ at room temperature in Tris$\mathrm{HCl}$ containing $20 \mathrm{nM}\left[{ }^{3} \mathrm{H}\right]\left[\mathrm{D}-\mathrm{Ala}^{2}-N\right.$-Me-Phe $\left.{ }^{4}, \mathrm{Gly}-\mathrm{ol}^{5}\right]$-enkephalin (DAMGO; Multiple Peptide Systems, San Diego, CA). After incubation, sections were washed in four changes, $30 \mathrm{sec}$ each, of ice-cold Tris-HCl. After the final wash, the slides were dipped in two changes of ice-cold distilled water for $5 \mathrm{sec}$ each to wash off salts. The slides were dried under a stream of cold air at $4^{\circ} \mathrm{C}$ and desiccated overnight at room temperature. Dried slides and ${ }^{3} \mathrm{H}$ autoradiographic standards (American Radiolabeled Chemicals, St. Louis, MO) were placed in apposition to Amersham (Arlington Heights, IL) Hyperfilm for 6 weeks. Films were developed in Kodak D-19 developer and fixed with Kodak fixer. Nonspecific binding was determined by processing paired serial sections as described above, except that $20 \mu \mathrm{M}$ nonradioactive DAMGO was added to the binding solution.

Analysis. Optical densities were measured on sections through the MPO and MeApd taken at four different anteroposterior levels using a computer-assisted image analysis system and expressed as nanocuries per milligram of standard. Sections used for autoradiography were thioninstained and used to define the MPO and MeA. Specific binding in each section was calculated by subtracting the nonspecific binding values obtained from its paired section from the total binding values. The average specific binding for each MPO or MeA was calculated, and the specific binding values across treatment groups were compared using one-way ANOVA (Sigma Stat; Jandel Scientific, San Rafael, CA).

\section{RESULTS}

\section{Antibody specificity}

No positive structures were observed in sections processed for immunocytochemistry without the $\mu$-OR antiserum. Preabsorption of the $\mu$-OR antiserum with the synthetic peptide fragment used to generate antibodies prevented immunostaining in tissue specimens and has previously been reported (Sternini et al., 1996; Olive et al., 1997). Moreover, the appearance and distribution of $\mu$-ORi in this study is similar to the distribution Mansour et al.
(1995) observed using a different polyclonal antibody generated against 63 amino acids $\left(\mu-\mathrm{OR}_{335-398}\right)$ of the $\mathrm{C}$ terminus of the cloned $\mu$-OR.

\section{Distribution of $\mu$-ORi in the limbic-hypothalamic circuit}

$\mu$-OR immunocytochemistry revealed a plexus of distinct immunoreactive fibers in the MPN, principal nucleus of the BST (BSTp), and MeApd (Fig. 4). The MPN $\mu$-ORi plexus extended the full rostrocaudal length of the medial preoptic area but was more pronounced in the dorsal aspect of the medial part of the MPN (MPNm). The medial preoptic plexus began rostrally in fibers surrounding the anteroventral periventricular nucleus and ended caudally at the anterior hypothalamic area. No $\mu$-ORi was observed in the cell-dense, central portion of the MPN (MPNc) although the rest of the MPNm contained a large amount of immunoreactivity (Fig. 4). The $\mu$-ORi plexus extended dorsally and laterally from the posterior MPN into the striohypothalamic nucleus and continued into the BSTp. $\mu$-ORi cell bodies were sparsely distributed in the MPN. The greatest density of immunoreactive cell bodies was observed in a continuous band from the most caudal portion of the MPN through the striohypothalamic nucleus.

$\mu$-ORi fibers form a plexus in the principal and the lateral strial portion of the BST (Fig. 4). The stria terminalis, a major neuronal pathway containing reciprocal projections between the amygdala and the BST, also exhibited dense $\mu$-ORi staining. A plexus of $\mu$-ORi fibers was also observed in the dorsolateral aspect of the MeApd. $\mu$-ORi was also present in the medial, central, and posteromedial cortical nuclei of the amygdala.

The globus pallidus, which is outside of the estrogen-sensitive, limbic-hypothalamic circuit and has a dense network of $\mu$-ORi fibers, was used as a control for the effects of estrogen on the distribution of $\mu$-ORi in these studies.

\section{Cellular distribution of $\boldsymbol{\mu}$-ORi in ovariectomized rats}

Confocal microscopy confirmed earlier work that the cellular localization of $\mu$-ORi in unstimulated animals was primarily 

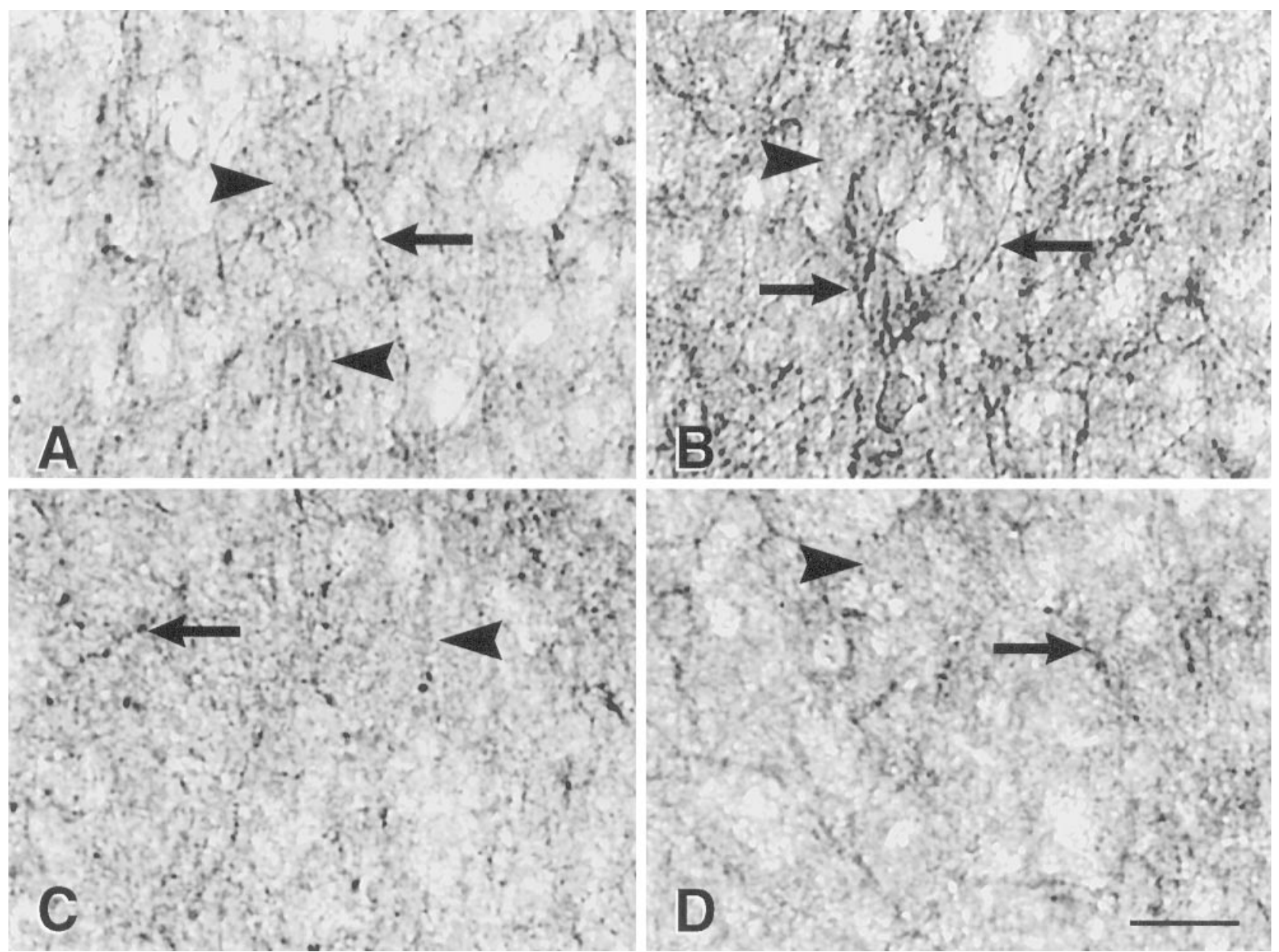

Figure 5. Bright-field photomicrographs of $\mu$-OR immunocytochemical localization in the medial MPN, dorsal to the central part of the MPN in the area quantified (Fig. 3). OVX animals $(A)$ had a low density of distinct $\mu$-OR + fibers $(A$, arrows). Although a number of distinct $\mu$-OR + fibers were detected (arrows), the majority of $\mu$-OR immunoreactivity was diff use $(A, C, D$, arrowheads). Treatment with estrogen produced a dramatic increase in the density of varicose $\mu$-OR + fibers at $4 \mathrm{hr}(B)$, but by $72 \mathrm{hr}(C)$ the distribution resembled tissue from ovariectomized rats. The estrogen-induced increase was blocked by pretreatment with naltrexone $(D)$. Scale bar: $D, 25 \mu \mathrm{m}$.

associated with cell membranes of neural processes and cell bodies (Sternini et al., 1996). In untreated OVX females, the preponderance of $\mu$-ORi appeared as patchy areas of fluorescence associated with the plasma membrane of cell bodies and presumptive dendrites throughout the MPN, BST, and MeApd (Figs. 1, 2). Scattered among the membrane-associated $\mu$-ORi profiles were thin varicose fibers in which $\mu$-ORi filled the cell body or process and that did not appear to be associated with the membrane.

Bright-field microscopy revealed a $\mu$-ORi that was generally diffuse and only occasionally associated with distinct neuronal processes and cell bodies in the nuclei of the limbic-hypothalamic circuit (Figs. 5, 6). $\mu$-ORi labeling within the OVX animals could be divided into two types: (1) the majority of labeling was on fibers with smooth, diffuse outlines and weakly labeled cells; and (2) the minority of labeling was in distinct immunoreactive processes with intensely labeled varicose fibers.

\section{Pattern of $\boldsymbol{\mu}$-ORi after stimulation}

Etorphine treatment has been shown to induce activation and internalization of $\mu$-ORi in cells transfected with the $\mu$-OR in vitro (von Zastrow et al., 1994) and enteric neurons in vivo (Sternini et al., 1996). In the brain, etorphine induced a rapid and reversible change in the subcellular localization but not the tissue distribution of $\mu$-ORi (Micevych et al., 1997; Keith et al., 1998). After etorphine treatment, the number of cell bodies and processes in which the $\mu$-ORi was localized within the structure was dramatically increased. In these structures, the immunoreactivity was not associated with the plasma membrane but was localized within processes in a pattern that is consistent with internalized receptors (Mantyh et al., 1995a,b; Sternini et al., 1996; Allen et al., 1997; Olive et al., 1997; Keith et al., 1998). This pattern of receptor internalization was correlated at the light microscopic level with an increase in the density of distinct varicose fibers throughout the brain, including the cortex, the globus pallidus, thalamus, lateral hypothalamus, and central amygdala. Moreover, the density of the $\mu$-ORi fibers within the plexuses in the MPN, BST, and MeA was increased.

As with etorphine, the tissue distribution of $\mu$-ORi was not changed by treatment with estrogen. Moreover, as with etorphine, confocal microscopic examination revealed that $\mu$-ORi was primarily internalized in cell bodies and processes of the MPN, BSTp, and the MeApd after estrogen treatment (Figs. 1, 2). At the light microscopic level, the number of distinctly labeled $\mu$-ORi fibers was increased in the limbic-hypothalamic nuclei 

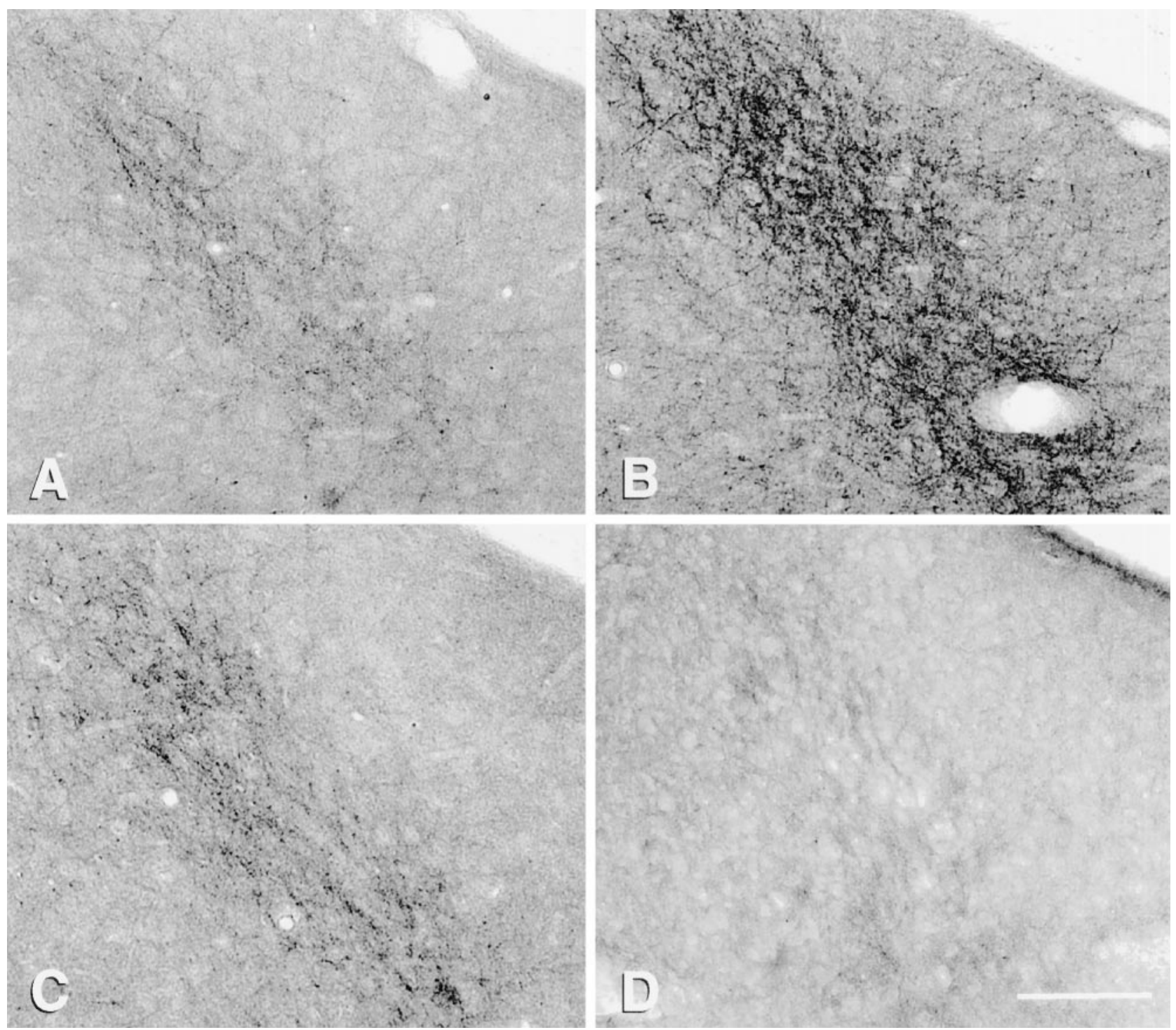

Figure 6. Bright-field photomicrographs of $\mu$-OR immunocytochemical localization in the posterodorsal medial amygdala in OVX $(A)$ and estrogentreated rats $(B, C, D)$. Estrogen induces an increase in the number of $\mu$-OR + fibers $4 \mathrm{hr}$ after estrogen $(B)$; by $72 \mathrm{hr}(C)$ the density is similar to OVX levels. Naltrexone blocks the estrogen effect $(D)$ and induces a significant decrease in the density of fibers. Scale bar: $D, 50 \mu \mathrm{m}$.

after estrogen treatment (Figs. 5, 6). In contrast to etorphinetreated rats, the increase in $\mu$-ORi processes after estrogen treatment was restricted to steroid-responsive regions of the brain. No increase in varicose $\mu$-ORi fibers was observed in the cortex, thalamic nuclei, central amygdaloid nuclei, or globus pallidus (Table 1).

Estrogen stimulation significantly increased the density of $\mu$-ORi processes in the MPN and MeApd within 30 min (Fig. 7, Table 1). This elevation of $\mu$-ORi processes remained for $24 \mathrm{hr}$ and then declined to basal levels by $48 \mathrm{hr}$. The density of $\mu$-ORi processes remained at this low level for the duration of the $96 \mathrm{hr}$ experiment. Treatment of ovariectomized rats with naltrexone $(10 \mathrm{mg} / \mathrm{kg})$ before stimulation with estrogen not only prevented the increase of $\mu$-ORi processes within the MPNm and MeApd but reduced the density of fibers to a significantly lower level than in unstimulated animals at $0 \mathrm{hr}$ (Fig. 7).

\section{$\boldsymbol{\mu}$-OR-specific binding}

Specific binding with $\left[{ }^{3} \mathrm{H}\right] \mathrm{DAMGO}$ was observed in the MeA and MPO at all time points (Fig. 8). Estrogen injection had no significant overall effect on $\mu$-OR-specific binding levels either in the MeA or in the MPO at any of the time points investigated.

\section{DISCUSSION}

To our knowledge, the present communication is the first report that indicates the $\mu$-OR is redistributed in response to a naturally occurring stimulus. Translocation of $\mu$-ORi from the plasma membrane to the interior of the cell after estrogen treatment was interpreted as agonist-induced receptor internalization. To date, most studies that examine opioid receptor internalization have been in transfected cells in vitro (von Zastrow et al., 1993; Arden et al., 1995; Keith et al., 1996, 1998). Such studies indicate that after the initial agonist-receptor interaction and signal transduction, $\mu$-ORs are typically internalized through the process of endocytosis into the endosomal compartment. The ligands are dissociated from the receptors, and some of the receptors are recycled back to the plasma membrane. There is a paucity of studies that have examined the activation of opioid receptors in vivo (Sternini et al., 1996; Keith et al., 1998). 


\begin{tabular}{|c|c|c|c|}
\hline \multirow[b]{2}{*}{ Treatment } & \multicolumn{3}{|c|}{ Immunoreactive fibers $/ 100 \mu \mathrm{m} \pm \mathrm{SE}$} \\
\hline & MPN & MeApd & Globus pallidus \\
\hline \multicolumn{4}{|l|}{ EB } \\
\hline $0 \mathrm{hr}$ & $6.66 \pm 0.32$ & $5.95 \pm 0.21$ & $6.96 \pm 0.10$ \\
\hline $0.5 \mathrm{hr}$ & $13.93 \pm 0.22^{*}$ & $10.32 \pm 0.33^{*}$ & $6.63 \pm 0.10$ \\
\hline $1 \mathrm{hr}$ & $13.14 \pm 0.55^{*}$ & $9.95 \pm 0.48^{*}$ & $6.62 \pm 0.16$ \\
\hline $2 \mathrm{hr}$ & $13.41 \pm 0.41^{*}$ & $10.63 \pm 0.20^{*}$ & $6.75 \pm 0.17$ \\
\hline $4 \mathrm{hr}$ & $14.07 \pm 0.92 *$ & $10.81 \pm 0.51^{*}$ & $7.20 \pm 0.14$ \\
\hline $6 \mathrm{hr}$ & $13.87 \pm 1.04^{*}$ & $11.35 \pm 0.34^{*}$ & $6.94 \pm 0.20$ \\
\hline $12 \mathrm{hr}$ & $12.20 \pm 0.73^{*}$ & $11.79 \pm 0.27^{*}$ & $6.75 \pm 0.20$ \\
\hline $24 \mathrm{hr}$ & $11.59 \pm 0.54^{*}$ & $11.27 \pm 0.40^{*}$ & $6.75 \pm 0.13$ \\
\hline $48 \mathrm{hr}$ & $5.72 \pm 0.55$ & $6.99 \pm 0.24$ & $7.04 \pm 0.17$ \\
\hline $72 \mathrm{hr}$ & $5.89 \pm 0.57$ & $6.80 \pm 0.17$ & $6.85 \pm 0.17$ \\
\hline $96 \mathrm{hr}$ & $5.96 \pm 0.30$ & $6.27 \pm 0.38$ & $6.75 \pm 0.17$ \\
\hline Naltrexone and EB, $4 \mathrm{hr}$ & $3.70 \pm 0.15^{* *}$ & $2.10 \pm 0.37^{* *}$ & $6.05 \pm 0.08^{* *}$ \\
\hline
\end{tabular}

*Significantly higher density of processes compared to $0 \mathrm{hr}$ animals $(p<0.05)$.

**Significantly lower density of processes compared to 0 and $4 \mathrm{hr}$ estrogen-treated animals $(p<0.05)$.

The present study used the idea, proposed by Mantyh et al. (1995b) and Allen et al. (1997), that translocation of G-proteincoupled receptors is a pharmacologically specific index of neuronal activity. Furthermore, agonist-induced endocytosis of a signal-transducing receptor is a valid method for identifying the anatomical components of highly specific neuronal circuits. These authors quantified the number of endosomes with the confocal microscope before and after stimulation. In the present study, we used the redistribution of immunoreactivity, which resulted in an increase of $\mu$-OR + processes, as a measure of $\mu$-OR activation in the limbic-hypothalamic circuit in response to estrogen stimulation. Several lines of evidence suggest that the increase of $\mu$-ORi fiber density we measured in this study is a marker for receptor internalization. First, in alternate sections using the confocal microscope, we observed a translocation of $\mu$-ORi from the plasma membrane to the intracellular compartment after estrogen treatment. The intracellular localization of $\mu$-ORi produced a concentration of immunoreactivity that allowed for the visualization of a greater number of fibers. Internalization of $\mu$-ORi was therefore correlated at the light microscopic level with an increase in the number of varicose $\mu$-ORi fibers after stimulation. Second, the same morphological reorganization and increase in the number of $\mu$-ORi processes observed in the limbic-hypothalamic cell groups after estrogen treatment was seen after etorphine treatment. Third, naltrexone blocked the estrogen-induced increase in immunoreactive processes, strongly suggesting that estrogen provoked the release of endogenous opioids that activated and induced the internalization of the $\mu$-ORi. Fourth, correlation of ultrastructural and light microscopic localization of the somatostatin sst $2 \mathrm{~A}$ receptor showed that diffuse labeling of processes at the light microscopic level is related to a membrane location of the receptor and distinct labeling of processes is correlated with internalized receptor immunoreactivity (Dournaud et al., 1997).

A process, other than internalization, that could produce an increase in immunoreactivity after estrogen treatment is an increase of $\mu$-OR expression. It could be argued that newly synthesized receptors would be localized in vesicles before their insertion into the membrane, and so the immunoreactivity would be predominately intracellular. However, estrogen stimulates $\mu$-OR
mRNA expression $48 \mathrm{hr}$ after treatment (Quinones-Jenab et al., 1997) (protein levels were not reported), and by the $48 \mathrm{hr}$ time point in the present study, the estrogen effect had passed (Fig. 7). Moreover, $\left[{ }^{3} \mathrm{H}\right.$ ]DAMGO binding levels do not change for $24 \mathrm{hr}$ after estrogen treatment (Fig. 8). The rapidity of the estrogen effect (30 min), similar time course and pattern of $\mu$-ORi redistribution after etorphine, and sensitivity to naltrexone also argue against the possibility of increased $\mu$-OR expression as the cause of the increased number of immunoreactive fibers.

In contrast to the extended time course of internalization after estrogenic activation, Mantyh et al. (1995b) showed that within 60 min after somatosensory stimulation, substance $\mathrm{P}$ receptor was no longer internalized. The extended internalization of the $\mu$-OR may be attributable to the prolonged clearance time of the steroid. A $50 \mu \mathrm{g}$ injection of EB maintains significantly elevated serum estrogen levels for $>24 \mathrm{hr}$, which return to baseline by 48 hr after estrogen treatment (Priest et al., 1995), suggesting that estrogen may induce continuous release of endogenous opioid peptides and $\mu$-OR internalization throughout this period.

Previous studies have implicated estrogen and progesterone in the regulation of opioid receptors in the MPN. Estrogen decreases and progesterone further decreases the number of $\mu$-OR binding sites in the MPN (Hammer, 1984, 1990; Weiland and Wise, 1990; Piva et al., 1995; but see Shen et al., 1995). These studies demonstrate a downregulation of the $\mu$-OR. In contrast, the present study examined short-term alterations of the cellular distribution of $\mu$-OR induced by estrogen. Agonist-induced internalization removes receptors from the plasma membrane, preventing further stimulation by ligands, but the numbers of receptors are not significantly altered (Lefkowitz et al., 1993; von Zastrow and Kobilka, 1994). Several studies have reported that estrogen does not alter the number of $\mu$-OR in the short term (Mateo et al., 1992; Shen et al., 1995). Similarly, our results that $\left[{ }^{3} \mathrm{H}\right] \mathrm{DAMGO}$ binding in the MPN and MeA did not fluctuate during the $24 \mathrm{hr}$ after estrogen treatment support the idea presented here that early estrogen regulation of the $\mu$-OR is the result of receptor internalization and desensitization and not downregulation.

The results of the present study suggest that estrogen induces a rapid release of the endogenous opioid peptides in the MPN, $\mathrm{BST}$, and MeA that activate $\mu$-OR in these regions. An important question is which endogenous opioids are being stimulated by estrogen. Endorphins, enkephalins, and dynorphins all have an $\mathrm{N}$ terminus (YGGFM/L) that binds with moderate specificity to the $\mu$-OR, $\delta$-OR, and $\kappa$-OR. There are several potential candidates in the limbic-hypothalamic circuit. Estrogen increases the expression of the enkephalin precursor preproenkephalin mRNA in the MPNm, MeApd, and ventromedial hypothalamus (Romano et al., 1989; Eckersell et al., 1994; Priest et al., 1995; Holland et al., 1997). Furthermore, the immunocytochemical distribution of $\beta$-endorphin increases on estrus, the day after estrogen levels peak during the estrous cycle (Ge et al., 1993), and $\beta$-endorphin fiber density in the MPNm varies with sex steroid levels (Hammer and Cheung, 1995). These fibers originate from cells in the arcuate nucleus that also respond to estrogen stimulation (Hammer et al., 1991). Because of their selectivity, endogenous peptides have been assigned to different opioid receptors; enkephalins are considered the endogenous ligands for $\delta$-OR. $\beta$-Endorphin binds to $\mu$-OR and $\delta$-OR with similar affinity (Lee and Smith, 1980; Patterson et al., 1983; Smith et al., 1983). Another likely candidate is the novel endogenous opioid peptide endomorphin-1, the putative endogenous ligand for the $\mu$-OR 


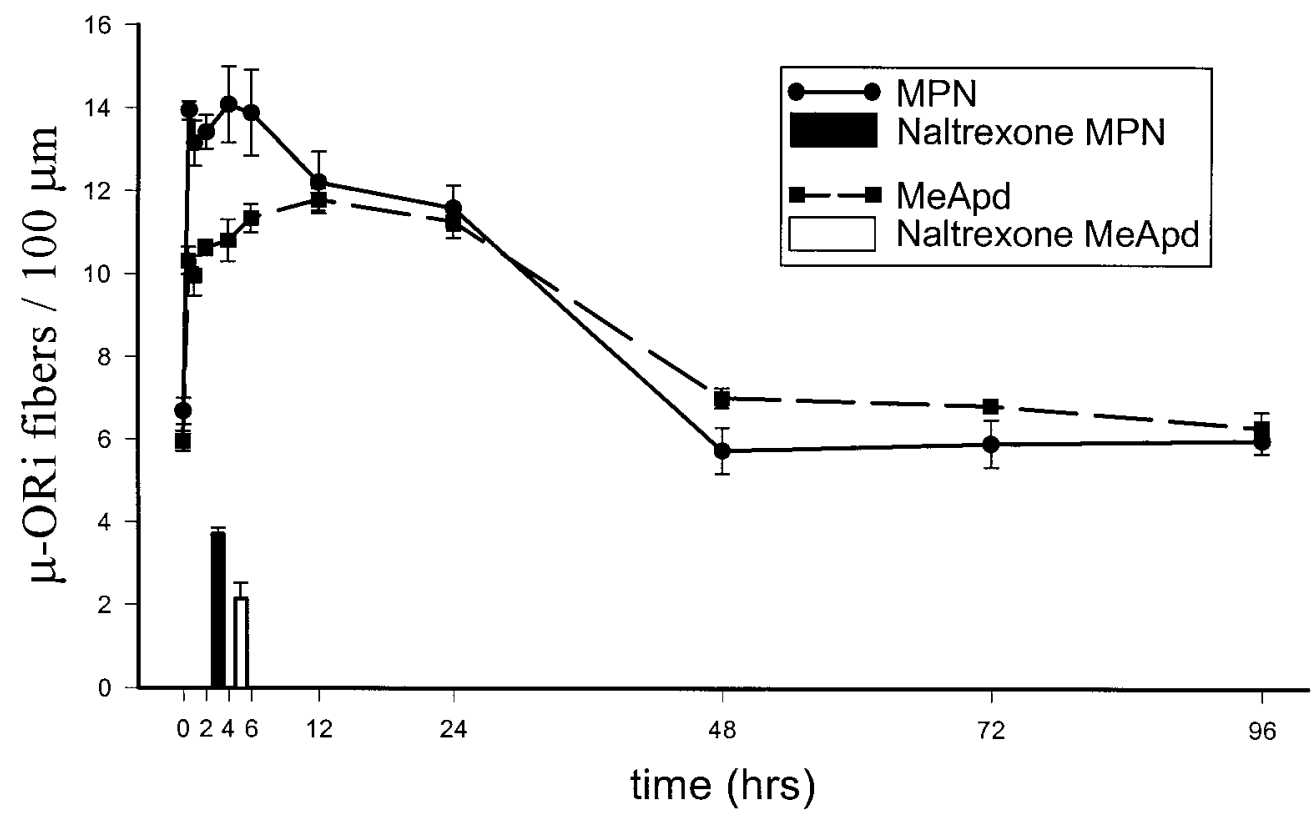

Figure 7. Graphic representation of the density of $\mu$-ORi fibers in the medial part of the MPN (MPNm) (solid line) and the posterodorsal medial amygdaloid nucleus (MeApd) (dashed line) after estrogen treatment. The moment of EB injections is time 0 . The density of distinct $\mu$-OR + fibers was significantly elevated by $30 \mathrm{~min}$ and peaks at $4-6 \mathrm{hr}$. The density of $\mu$-OR+ fibers is basal by $48 \mathrm{hr}$. The bars at the $4 \mathrm{hr}$ time point illustrate the density of $\mu$-OR + fibers in the MPNm (solid bar) and MeApd (open bar) in OVX plus EB rats pretreated with naltrexone 24 and 4 hr before perfusion. The density of $\mu$-OR + fibers in the naltrexone-treated rats is significantly lower than in ovariectomized rats in the MPN and MeApd. Each point is the mean $\pm \operatorname{SEM}(n=4$ per time point $)$.

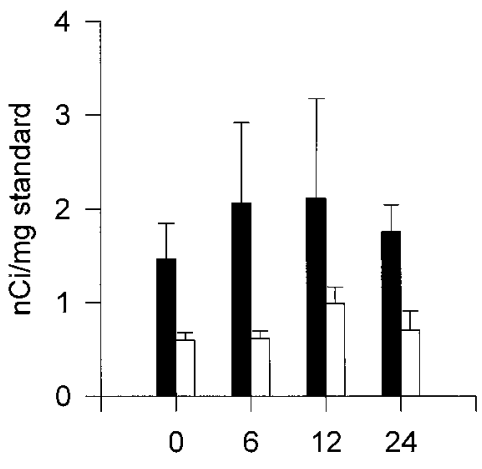

Hours after estrogen

Figure 8. Histogram showing $\left[{ }^{3} \mathrm{H}\right] \mathrm{DAMGO}$ binding in the MeA (solid bar) and MPO (open bar) at $0,6,12$, and $24 \mathrm{hr}$ after subcutaneous injection of $50 \mu \mathrm{g}$ of EB. No significant change in $\left[{ }^{3} \mathrm{H}\right] \mathrm{DAMGO}$ binding was observed in either the MeA or MPO after estrogen injection. Each point is the mean $\pm \operatorname{SEM}(n=4$ per time point $)$.

that is concentrated in the hypothalamus (Zadina et al., 1997). The characterization of the endogenous ligand(s) that are released in the limbic-hypothalamic circuit to activate $\mu$-OR will require further investigation.

Both direct and indirect evidence suggests that endogenous opioids regulate sexual receptivity through activation of $\mu$-OR. Systemic treatment of estrogen-primed OVX rats with naloxone, an opioid antagonist, facilitated sexual receptivity, as measured by lordosis behavior (Wiesner and Moss, 1986a), and site-specific injections of $\beta$-FNA, a $\mu$-OR antagonist, into the MPN also increased lordosis behavior in estrogen-primed female rats (Hammer et al., 1989). Further injections of the selective, endogenous $\mu$-OR agonist endomorphin-1 into the MPN blocked lordosis in estrogen- and progesterone-primed females (K. Sinchak,
C. Evans, N. Maidment, and P. Micevych, unpublished observations). Also, infusions of $\beta$-FNA into the MPN attenuated the estrogen-stimulated release of cholecystokinin, a neuropeptide that facilitates lordosis in the MPN (Sinchak et al., 1997b). These findings, therefore, are consistent with the hypothesis that endogenous opioid peptides released in the MPN act at the $\mu$-OR to decrease sexual receptivity.

It is clear that a number of transmitters in addition to the endogenous opioids are involved in the integrated signaling of the limbic-hypothalamic nuclei that regulate reproductive behavior. The present results suggest that by studying the redistribution of receptors in this circuit, it may be possible to define the neurochemical signature (Allen et al., 1997) and temporal sequence of hormonal activation of the brain. Such an analysis will allow for a more complete understanding of estrogen activation of neural circuits.

\section{REFERENCES}

Allen DL, Johnson AE, Tempel A, Zukin RS, Luine VN, McEwen BS (1993) Serotonergic lesions decrease mu- and delta-opiate receptor binding in discrete areas of the hypothalamus and in the midbrain central gray. Brain Res 625:269-275.

Allen BJ, Rogers SD, Ghilardi JR, Menning PM, Kuskowski MA, Basbaum AI, Simone DA, Mantyh PW (1997) Noxious cutaneous thermal stimuli induced a graded release of endogenous substance $\mathrm{P}$ in the spinal cord: imaging peptide action in vivo. J Neurosci 17:5921-5927.

Arden JR, Segredo V, Wang Z, Lameh J, Sadee W (1995) Phosphorylation and agonist-specific intracellular trafficking of an epitope-tagged mu-opioid receptor expressed in HEK 293 cells. J Neurochem 65:1636-1645.

Bhanot R, Wilkinson M (1983) Opiatergic control of gonadotropin secretion during puberty in the rat: a neurochemical basis for the hypothalamic "gonadostat"? Endocrinology 113:596-603.

Bicknell RJ (1985) Endogenous opioid peptides and hypothalamic neuroendocrine neurones. J Endocrinol 107:437-446.

Caron MG, Lefkowitz RJ (1993) Catecholamine receptors: structure, function, and regulation. Recent Prog Horm Res 48:277-290. 
Cicero TJ, Schainke BA, Meyer ER (1979) Endogenous opioids participate in the regulation of the hypothalamus-pituitary-luteinizing hormone axis and testosterone's negative feedback control of luteinizing hormone. Endocrinology 104:1286-1291.

Dournaud P, Boudin H, Schonobrunn A, Tannenbaum GS, Beaudet A (1997) Relationship between somatostatin and the somatostatin sst2A receptor in rat brain: a light, confocal and electron microscopic double labeling study. Soc Neurosci Abstr 23:1138.

Dupont A, Barden N, Cusan L, Merand Y, Labrie F, Vaudry H (1980) Beta-endorphin and met-enkephalins: their distribution, modulation by estrogens and haloperidol and role in neuroendocrine control. Fed Proc 39:2544-2550.

Eckersell CB, Micevych PE (1997) Opiate receptors modulate estrogeninduced cholecystokinin and tachykinin but not enkephalin mRNA levels in the limbic system and hypothalamus. J Neurosci 80:473-485.

Eckersell CB, Mills RH, Bloch GJ (1992) Sex steroids and galaninimmunoreactive (GAL-I) cells in the medial preoptic area (MPOA): cell size and male-specific plexus. Soc Neurosci Abstr 18:818.

Eckersell CB, Priest CA, Micevych PE (1994) Temporal regulation of preproenkephalin-A mRNA expression by estrogen in the posterior dorsal medial amygdala of the female rat. Soc Neurosci Abstr 20:1770.

Eckersell CB, Popper P, Micevych PE (1996) Stress up-regulates preproenkephalin (PPE) mRNA levels in the limbic system and hypothalamus of the female rat. Soc Neurosci Abstr 22:1415.

Garland AM, Grady EF, Lovett M, Vigna SR, Frucht MM, Krause JE, Bunnett NW (1996) Mechanisms of desensitization and resensitization of G-protein-coupled neurokinin 1 and neurokinin 2 receptors. Mol Pharmacol 49:438-46.

Ge F, Hammer Jr RP, Tobet SA (1993) Ontogeny of Leu-enkephalin and beta-endorphin innervation of the area in male and female rats. Brain Res Dev Brain Res 73:273-281.

Hammer RP (1984) The sexually dimorphic region of the preoptic area in rats contains denser opiate receptor binding sites in females. Brain Res 308:172-176.

Hammer RP (1990) Mu-opiate receptor binding in the medial preoptic area is cyclical and sexually dimorphic. Brain Res 515:187-192.

Hammer RP, Cheung S (1995) Sex steroid regulation of hypothalamic opioid function. In: Neurobiological effects of sex steroid hormones (Micevych PE, Hammer RP, eds), pp 143-159. New York: Cambridge UP.

Hammer RP, Dornan WA, Bloch GJ (1989) Sexual dimorphism and function of the $\mu$-opiate receptors in the rat medial preoptic area: involvement in regulation of lordosis behavior. Int Conf Horm Brain Behav Abstr 77-78.

Hammer RP, Brady LS, Abelson L, Micevych PE (1991) Differential localization of opioid neurons projecting to the medial preoptic nucleus. Anat Rec 229:35a.

Holland KL, Abelson L, Micevych PE (1998) Ontogeny and estrogen regulation of prepubertal CCK and preproenkephalin mRNA in the hypothalamus and limbic system. J Comp Neurol 398:48-57.

Jacobson W, Kalra SP (1989) Decreases in mediobasal hypothalamic and preoptic area opioid $\left(\left[{ }^{3} \mathrm{H}\right]\right.$ naloxone $)$ binding are associated with the progesterone-induced luteinizing hormone surge. Endocrinology 124:199-206.

Kalra SP (1986) Neural circuitry involved in the control of LHRH secretion: a model for preovulatory $\mathrm{LH}$ release. In: Frontiers in neuroendocrinology, Vol 9 (Ganong WF, Martini L, eds), pp 31-75. New York: Raven.

Kalra SP, Kalra PS (1984) Opioid-adrenergic-steroid connection in regulation of luteinizing hormone secretion in the rat. Neuroendocrinology 38:418-426.

Keith DE, Murray SR, Zaki PA, Chu PC, Lissin DV, Kang L, Evans CJ, von Zastrow M (1996) Morphine activates opioid receptors without causing their rapid internalization. J Biol Chem 271:19021-19024.

Keith DE, Anton B, Murray SR, Zaki PA, Chu PC, Lissin DV, Monteillet-Agius G, Stewart PL, Evans CJ, von Zastrow M (1998) Mu opioid receptor internalization: opiate drugs have differential effects on a conserved endocytic mechanism in vitro and in the mammalian brain. Mol Pharmacol, in press.

Kobilka B (1992) Adrenergic receptors as models for G-protein-coupled receptors. Annu Rev Neurosci 15:87-114.

Lee NM, Smith AP (1980) A protein-lipid model of the opiate receptor. Life Sci 26:1459-1464.

Lefkowitz RJ, Cotecchia S, Kjelsberg MA, Pitcher J, Koch WJ, Inglese J, Caron MG (1993) Adrenergic receptors: recent insights into their mechanism of activation and desensitization. Adv Second Messenger Phosphoprotein Res 28:1-9.

Mansour A, Fox CA, Burke S, Akil H, Watson SJ (1995) Immunohistochemical localization of the cloned mu opioid receptor in the rat CNS. J Chem Neuroanat 8:283-305.

Mantyh PW, Allen CJ, Ghilardi JR, Rogers SD, Mantyh CR, Liu H, Basbaum AI, Vigna SR, Maggio JE (1995a) Rapid endocytosis of a G-protein-coupled receptor: substance P evoked internalization of its receptor in the rat striatum in vivo. Proc Natl Acad Sci USA 92:2622-2626.

Mantyh PW, DeMaster E, Malhotra A, Ghilardi JR, Rogers SD, Mantyh CR, Liu H, Basbaum AI, Vigna SR, Maggio JE, Simone DA (1995b) Receptor endocytosis and dendrite reshaping in spinal neurons after somatosensory stimulation. Science 268:1629-1632.

Mateo AR, Hijazi M, Hammer Jr RP (1992) Dynamic patterns of medial preoptic mu-opiate receptor regulation by gonadal steroid hormones. Neuroendocrinology 55:51-58.

Micevych PE, Eckersell CB, Holland KL, Smith A (1996) Induction of CCK mRNA levels in the limbic-hypothalamic circuit: time course and site-specific effects of estrogen. J Neurobiol 30:465-479.

Micevych PE, Eckersell CB, Brecha N, Holland K (1997) Estrogenic modulation of opiate and cholecystokinin systems in the limbichypothalamic circuit. Brain Res Bull 44:325-334.

Olive MF, Anton B, Micevych PE, Evans CJ, Maidment NT (1997) Presynaptic versus postsynaptic localization of mu and delta opioid receptors in dorsal and ventral striatopallidal pathways. J Neurosci 17:7471-7479.

Olster DH (1994) Opiate receptor blockade enhances the display of progesterone-facilitated lordosis in juvenile female guinea pigs. Horm Behav 28:84-95.

Patterson SJ, Robson LE, Kosterlitz HW (1983) Classification of opiate receptors. Br Med Bull 39:31-36.

Pfaus JG, Gorzalka BB (1987) Selective activation of opioid receptors differentially affects lordosis behavior in female rats. Peptides 8:309-317.

Pfaus JG, Pfaff DW (1992) Mu-, delta-, and kappa-opioid receptor agonists selectively modulate sexual behaviors in the female rat: differential dependence on progesterone. Horm Behav 26:457-473.

Piva F, Maggi R, Limonta P, Motta M, Martini L (1985) Effect of naloxone on luteinizing hormone, follicle-stimulating hormone, and prolactin secretion in the different phases of the estrous cycle. Endocrinology 117:766-772.

Piva F, Limonta P, Maggi R, Martini L (1986) Stimulatory and inhibitory effects of the opioids on gonadotropin secretion. Neuroendocrinology 42:504-512.

Piva F, Limonta P, Dondi D, Pimpinelli F, Martini L, Maggi R (1995) Effects of steroids on the brain opioid system. J Steroid Biochem Mol Biol 53:343-348.

Priest CA, Eckersell CB, Micevych PE (1995) Estrogen regulates preproenkephalin-A mRNA levels in the rat ventromedial nucleus: temporal and cellular aspects. Brain Res Mol Brain Res 28:251-262.

Quinones-Jenab V, Jenab S, Ogawa S, Inturrisi C, Pfaff DW (1997) Estrogen regulation of mu-opioid receptor mRNA in the forebrain of rats. Brain Res Mol Brain Res 47:134-138.

Rodriguez RE, Benson B, Dunn AM, Wise ME (1993) Age-related changes in biogenic amines, opiate, and steroid receptors in the prepubertal bull calf. Biol Reprod 48:371-376.

Romano GJ, Mobbs CV, Howells RD, Pfaff DW (1989) Estrogen regulation of proenkephalin gene expression in the ventromedial hypothalamus of the rat: temporal qualities and synergism with progesterone. Brain Res Mol Brain Res 5:51-58.

Senogles SE, Spiegel AM, Padrell E, Iyengar R, Caron MG (1990) Specificity of receptor-G-protein interactions. Discrimination of $\mathrm{Gi}$ subtypes by the D2 dopamine receptor in a reconstituted system. J Biol Chem 265:4507-4514.

Shen PJ, Smith AI, Evans RG, Clarke IJ (1995) Effects of ovarian steroids on hypothalamic opioid receptor subtypes in ovariectomized ewes: regional changes in density and affinity. J Endocrinol 145:559-567.

Sinchak K, Hendricks DG, Baroudi R, Micevych PE (1997a) Orphanin $\mathrm{FQ} /$ nociceptin in the ventromedial nucleus facilitates lordosis in female rats. NeuroReport 8:3857-3860.

Sinchak K, Maidment NT, Micevych PE (1997b) Temporal regulation of cholecystokinin release by estrogen in medial preoptic area of female 
rats measured by microdialysis and solid phase radioimmunoassay. Soc Neurosci Abstr 23:2138.

Sirinathsinghji DJ, Motta M, Martini L (1985) Induction of precocious puberty in the female rat after chronic naloxone administration during the neonatal period: the opiate 'brake' on prepubertal gonadotrophin secretion. J Endocrinol 104:299-307.

Smith A, Lee N, Loh H (1983) The multiple-site beta-endorphin receptor. Trends Pharmacol 4:163-164.

Sternini C, Spann M, Anton B, Keith Jr DE, Bunnett NW, von Zastrow M, Evans C, Brecha NC (1996) Agonist-selective endocytosis of mu opioid receptor by neurons in vivo. Proc Natl Acad Sci USA 93:9241-9246.

Torii M, Kubo K, Sasaki T (1995) Naloxone and initial estrogen action to induce lordosis in ovariectomized rats: the effect of a cut between the septum and preoptic area. Neurosci Lett 195:167-170.

Torii M, Kubo K, Sasaki T (1996) Influence of opioid peptides on the priming action of estrogen on lordosis in ovariectomized rats. Neurosci Lett 212:68-70.

Vathy I, van der Plas J, Vincent PA, Etgen AM (1991) Intracranial dialysis and microinfusion studies suggest that morphine act in the ventromedial hypothalamus to inhibit female rat sexual behavior. Horm Behav 25:354-366.

von Zastrow M, Kobilka BK (1994) Antagonist-dependent and -independent steps in the mechanism of adrenergic receptor internalization. J Biol Chem 269:18448-18452.

von Zastrow M, Link R, Daunt D, Barsh G, Kobilka B (1993) Subtype- specific differences in the intracellular sorting of G-protein-coupled receptors. J Biol Chem 268:763-766.

von Zastrow M, Keith D, Zaki P, Evans C (1994) Intracellular trafficking of epitope-tagged opioid receptors different effects of morphine and enkephalin. Regul Pept 54:315-316.

Weiland NG, Wise PM (1990) Estrogen and progesterone regulate opiate receptor densities in multiple brain regions. Endocrinology 126:804-808.

Wiesner JB, Moss RL (1986a) Behavioral specificity of beta-endorphin suppression of sexual behavior: differential receptor antagonism. Pharmacol Biochem Behav 24:1235-1239.

Wiesner JB, Moss RL (1986b) Suppression of receptive and proceptive behavior in ovariectomized, estrogen-progesterone-primed rats by intraventricular beta-endorphin: studies of behavioral specificity. Neuroendocrinology 43:57-62.

Wilkinson M, Bhanot R (1982) A puberty-related attenuation of opiate peptide-induced inhibition of LH secretion. Endocrinology 110:1046-1048.

Zadina JE, Hackler L, Ge LJ, Kastin AJ (1997) A potent and selective endogenous agonist for the mu-opiate receptor. Nature 386:499-502.

Zhen S, Gallo RV (1992) The effect of blockade of kappa-opioid receptors in the medial basal hypothalamus and medial preoptic area on luteinizing hormone release during midpregnancy in the rat. Endocrinology 131:1650-1656. 